\title{
Optimization of an automated smoke control system in an industrial atrium
}

\begin{abstract}
Pool fires are the most common hazard in many industrial applications. Therefore, automated fire control systems and occupational safety design codes and procedures are of major importance in industrial building systems design. Smoke is the main factor that causes deaths and casualties in fires. Thus, fire safety engineering (FSE) considers smoke management system as one of the most important factors. In this study, smoke generation during pool fire is numerically simulated to optimize the smoke management system. The smoke and temperature distributions inside a mechanically ventilated atrium are simulated using a computational fluid dynamic (CFD) transient model after initiating a diesel pool fire in the worst case scenario. Four numerical models are simulated and their results are compared to choose the model that optimizes smoke control. The models enable better approximations of the underlying physical phenomena in smoke transport for a single phase gas mixture. A velocity field approach is predicted using a turbulent standard $\mathrm{k}-\varepsilon$ model to study the domain with smoke plume. The ability to demonstrate and predict the flow field inside the atrium while the roof exhaust fans are operating is also investigated. The study aids in smoke management systems' design and helps to better understand of smoke plume behavior inside large spaces.
\end{abstract}

Keywords: smoke management, navier-stokes equations, reynolds-averaged navierstokes equations, pool fire, CFD simulation

\section{Introduction}

Pool fires due to liquids leaking from transformers, generators or other machinery are significant hazard to industrial facilities. ${ }^{1}$ The importance of modeling smoke movement during pool fires in large and complex buildings, e.g. malls and atria either naturally or forcibly ventilated, has been a subject of intensive research. Most of the fires' effects are due to the smoke produced by the fire rather than the fire itself e.g. decreased visibility, eyes irritation, reduction in the ability to identify escape routes, asphyxia and lung inflammation. ${ }^{2}$ Statistics revealed that hot and toxic smoke is responsible for about $85 \%$ of deaths in such typical events. ${ }^{3}$ Since there is no relevant provisions on atrium geometry, fire load, and smoke exhaust fan start-up time and other factors influencing smoke evacuation effect, it is necessary to do further studies of the mechanical smoke exhaust systems to improve the existing fire technical regulations and propose some feasible specifications of atrium smoke evacuation system. ${ }^{4}$ For fire and smoke modeling inside atriums, two numerical approaches were developed: the zone model and the field model. In the zone model approach, the atrium domain is separated into a hot smoke upper layer, due to buoyancy, while underneath is a cold fresh air layer. Both layers are assumed to have homogeneous properties. ${ }^{5}$ Zone models have been used for atrium smoke modeling and several researches have been done to assess its accuracy. ${ }^{6-9}$ In field models, partial differential equations expressing flow, species and energy conservation equations are all solved on the entire atrium domain that is discretized into small control volumes. Field models utilize the CFD technique which gives information about the risks within large enclosed spaces. The CFD studies the fluid flow problems using computational techniques, in contrast with to analytical and experimental methods. The CFD technique also provides valuable information on possible design strategies and intervention procedures that allows the minimization of fire risks. ${ }^{2}$ The CFD technique has proved to be more accurate than zone models that have limitations due to the simplifications and assumptions made, yet it is more expensive computationally., ${ }^{1,5,10-12}$
Volume 4 Issue I - 2019

\author{
Iman Mohamad Sharaf,' Ghada El-Sawah² \\ 'Department of Basic Sciences, Higher Technological Institute, \\ Tenth of Ramadan City, Egypt \\ ${ }^{2}$ Department of Mechanical Engineering, Higher Technological \\ Institute, Tenth of Ramadan City, Egypt
}

\begin{abstract}
Correspondence: Ghada El-Sawah, Department of Mechanical Engineering, Higher Technological Institute, Tenth of Ramadan
\end{abstract} City, Egypt, Email iman_sharaf@hotmail.com

Received: April 13, 2018 | Published: February 28, 2019
Both zone model and field model were combined in a study to best utilize their optimum benefits while simulating complex multicompartments. ${ }^{13} \mathrm{CFD}$ techniques vary widely among different models used in practice. While some CFD codes assume smoke as a gaseous mixture of dissolved gases, i.e. $\mathrm{CO}_{2}, \mathrm{CO}$ and $\mathrm{H}_{2} \mathrm{O}$, other approaches assume smoke as solid particulates in a two-phase Lagrangian assumption and argued that this better describe smoke coagulation and aggregation especially when fire extinguishing is taking place. ${ }^{14}$

CFD modelers were also concerned with fire and combustion modeling. Two approaches were developed: a non-combustion approach that argued that reaction details are not important as far as the larger view of atrium smoke transport is concerned, and another approach that uses a combustion model to best describe oxygen depletion, soot formation, plume turbulence and most importantly fire spread. ${ }^{15}$ CFD proved to be the most preferred approach capable of modeling the turbulence associated with pool fires due to its ability to enable closer approximation of the underlying physical phenomena. ${ }^{16}$ Numerous studies were done to compare CFD atrium models for smoke transport with experimental or empirical results and the outcomes were satisfactory. In complex models, Fire is usually represented by one of three typical approaches: fixed source of heat and smoke, source term that emits fuel or a mixture of fuel and oxygen, or a model of materials that have a mass and are the source of fuel through pyrolysis and evaporation. Each of them can be implemented either as a 2D source (surface) or a 3D source (volume), depending on the solver. ${ }^{17}$ In this study, the first approach is adopted in which fire is simulated as fixed source of heat and smoke, which is described by its generation rates, with the amount of energy and mass of combustion products emitted. The fire scenario, for the design of smoke management systems, must be typical to the expected fire in the atrium according to the atrium design and use. Two criteria must be considered, fire size and fire location. According to Lougheed, ${ }^{18}$ the minimum fire for fuel-restricted atrium is $2 \mathrm{MW}$. The fire location is either on the atrium floor or in a communicating space; with the 
fire on the floor in the center representing the worst case scenario (the symmetry of the smoke plume will entrain air on all sides producing the greatest volume of smoke). The most commonly used approaches in designing smoke management systems assume a steady state design fire or a fire that grows over time. A system that handles a steady state fire design, in which the fire is always the same, is able to deal with growing fires and also gives a large factor of safety as it assumes the largest possible fire from the time of ignition. ${ }^{18}$ The combustible material has a significant impact on the heat release rate (HRR) evolution and propagation, ${ }^{19}$ e.g. gasoline generates high temperature and polluting smoke. ${ }^{20}$ In this study $1 \mathrm{~m}$ diameter diesel pool fire of $\mathrm{HRR}=3 \mathrm{MW} / \mathrm{m}^{3}$, in the worst case scenario, is initiated.

The Industry codes have been issued to aid in smoke management designs. In its effort to introduce the most widely used fire safety codes, the National Fire Protection Association (NFPA), has issued the 92B code "Guide for Smoke Management Systems in Atria, Malls and Large Areas" that provides important recommendations for smoke ventilation design engineers on smoke layer formation, plume properties, smoke layer location and smoke exhaust methods by mechanical ventilation that is the main issue in this research. ${ }^{21}$ Smoke is mainly managed either by naturally venting it from roofs/ceilings or by mechanically extracting it by forced ventilation methods. The main intent of mechanical smoke exhaust is to prevent the hazardous hot smoke layer that is initially formed at the ceiling of the atrium from descending downwards to the level of occupants' walking zone and being mixed with the air in the atrium and connected communication spaces and stories, thus, enabling safe evacuation and refuge. When using a mechanical system to control smoke, the capacity of smoke exhaust fans should be carefully determined to prevent plug-holing; the smoke vent does not pump smoke, but pumps a great deal of air under the smoke layer due to high exhaust rates. ${ }^{20}$ Smoke exhaust efficiency will decrease significantly when ceiling extraction increases to draw directly fresh air beneath the smoke layer. The smoke plug-holing possibility decreases with increasing the number of extraction opening. ${ }^{22}$ The degree of openness and ventilation of the atrium is also a critical factor in the design of the system, since the fire burning rates is the starting point of any fire safety analysis. It should be noted that the burning rate in confined spaces, possibly coupled with mechanical ventilation systems, can be significantly different from the open atmosphere. ${ }^{23}$ In simulating pool fire, the most important parameter that determines the overall structure of a pool fire is turbulence. Turbulence determines the extent of interaction of various parameters including combustion; wind velocity and the entrainment of the ambient air. ${ }^{16}$

Pool fires have a specific physical behavior as discussed in many literatures. ${ }^{24-28}$ Fire was widely simulated using a combustion model that captures certain pool fire flame characteristics. Combustion models have proved to be more accurate in terms of simulating flame detailed physics and associated exhaust gases' concentrations. Meanwhile, such models still make important assumptions involving simple chemical kinetics. Other approaches ${ }^{10}$ have simulated the pool fire with a volumetric heat source in a natural convection scenario that will enable buoyant forces to from the flame structure. Such non-combustion models, though providing less accurate fire representation, are more robust and flexible when it comes to engineered solutions or predictions where detailed flame physics are not of concern in the designed system (i.e. fixed fire sources without fire spreading). So, instead of using a combustion model, fire is modeled with a different technique that has been reported acceptable in a previous benchmark comparison with a compartmented fire experiment. ${ }^{29}$ Recently, the performance of several $\mathrm{k}-\varepsilon$ turbulence models was assessed. It was shown that the standard k- $\varepsilon$ model enabled the closest CFD simulation of the experimental results. ${ }^{16}$ The available safe egress time (ASET), the amount of time that elapses between fire ignition and the development of untenable conditions (obscuration, high temperature, and toxicity) are calculated according to tenability criteria, e.g. visibility must remain above a certain height, temperature must remain below a specified value, or carbon monoxide concentration must remain below the permissible parts per million (ppm) ${ }^{30}$ Recently, Wegrzynski and Vigne ${ }^{17}$ investigated ASET related to smoke visibility, with increasing soot yield, and translated it to fire safety engineering design process, qualitative assessment of the results was performed with $\mathrm{k}-\varepsilon$ turbulence model. This study focuses on two factors that affect tenability criteria: the concentration of carbon dioxide and the temperature. Carbon dioxide, as a fire product, though non-toxic at concentrations lower than 5\%, it stimulates breathing. Thus, at $3 \%$ the volume of air breathed during a minute is approximately doubled and at 5\% tripled. This hyperventilation increases the rate at which other toxic fire products, such as carbon monoxide and hydrogen cyanide, are inhaled, reducing remarkably the time to suffocation and death. ${ }^{31}$ Protracted exposure for more than 15 minutes to high temperature may cause heat stroke (hyperthermia). Even for short durations, exposure to hot smoke at high temperatures may cause skin and respiratory tract burns without direct contact. ${ }^{30}$ The study determines the optimum number of smoke exhaust fans and the smoke extraction rate to increase the ASET, by decreasing the temperature and the carbon dioxide concentration, not only for workers to evacuate, but also to give them time to clear any flammable or combustible materials in the atrium. In this article a fire event with mechanical smoke exhaust will be simulated in an atrium space in an industrial facility using a CFD tool. The steady pool fire in an atrium space has been simulated in the three dimensional domain shown in Figure 1. Through transient analysis, smoke transport, heat transfer and flow dynamics will be simulated using a CFD model while fire and smoke extraction by the roof exhaust fans is taking place. Four numerical models will be simulated and their results are compared to choose the model that optimizes smoke control. For the three-dimensional approach adopted herein, this research assumes an axisymmetric smoke plume that is valid in atria with high aspect ratios.
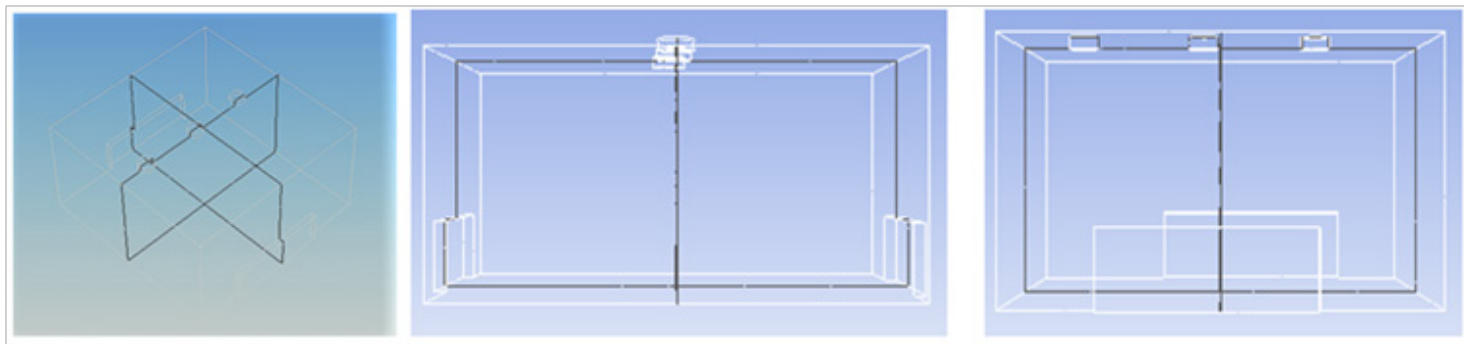

Figure I Configuration of the atrium's domain and cross section planes. 


\section{Brief theoretical background}

The fundamental governing equations of fluid dynamics (the continuity, the momentum and the energy equations) are the basis of CFD. The finite control volume is either moving with the fluid or fixed in space with the fluid moving through it. The PDEs obtained from the finite control volume moving with the fluid are called the non-conservation form of the governing equations. While the PDEs obtained from the finite control volume fixed in space are called the conservation form of the governing equations. The modelling of fluid flow leads to the solution of unsteady, non-linear partial differential equations (PDEs) representing conservation laws for the mass, momentum, and energy. The strong conservation form of the NavierStokes PDEs in compact vector differential form is given by

$$
\begin{aligned}
& \frac{\partial \rho}{\partial t}+\nabla \cdot(\rho \mathbf{V})=0, \\
& \frac{\partial(\rho \mathbf{V})}{\partial t}+\nabla \cdot(\rho \mathbf{V} \times \mathbf{V})=-\nabla p+\nabla \cdot \tau+\rho g, \\
& \frac{\partial\left(\rho e_{t}\right)}{\partial t}+\nabla \cdot\left(\rho e_{t} \mathbf{V}\right)=\kappa \nabla \cdot \nabla T+\nabla p \cdot \mathbf{V}+(\nabla \cdot \tau) \cdot \mathbf{V},
\end{aligned}
$$

where, $\mathbf{V}=u \underline{i}+v \underline{j}+w \underline{\mathrm{k}}$ is the velocity vector, $\rho$ is the scalar density field, $p$ is the pressure, $T$ is the temperature, $\kappa$ is the thermal conductivity, $\tau$ is the viscous stresses, $g$ is the gravity acceleration vector, $e_{t}$ is the total energy ( the sum of the internal energy and the kinetic energy per unit mass) and $\frac{\partial}{\partial t}$ is the local derivative, i.e. the time rate of change at a fixed point. For modelling turbulent flows, Reynolds-averaged Navier-Stokes equations (RANS) are employed. They are used to give approximate time-averaged solutions to NS equations. The instantaneous quantity is decomposed into its timeaveraged and fluctuating quantities; under the assumption that the time dependent turbulent velocity fluctuations can be separated from the mean flow velocity. The decomposition of the NS equations to RANS equations facilitates the simulation of the practical flows used within the CFD. The CFD decomposes a fluid domain into a mesh and then solves the RANS and conservation laws in each cell, by replacing the PDEs with a set of algebraic equations. The accuracy of the CFD simulation is determined by the mesh resolution and the turbulence model. The stress created by turbulent motion of vortices can be considered analogous to the viscous stress caused by molecules random motion. The viscous stress is the product of the viscosity and the velocity gradient. A model that computes the eddy viscosity only from the RANS is called the zero equation model, a model that utilize a transport equation that is solved simultaneously with the RANS is called a one equation model, and the model that uses two parameters is called the two equation model. For a two equation model, numerous models were proposed depending on how the parameters are chosen. The most widely used model is the $\mathrm{k}-\varepsilon$ model, where $\mathrm{k}$ is the turbulence kinetic energy, and $\varepsilon$ is the rate of kinetic energy dissipation per unit mass. $^{32}$

\section{Numerical model}

\section{Description of the simulated atrium}

The present study focuses on the smoke movement model and investigates the temperatures achieved in an industrial atrium with $20 \mathrm{~m} \times 20 \mathrm{~m} \times 10 \mathrm{~m}$ dimensions under the conditions of mechanical ventilation. The shape coefficient $\zeta=\mathrm{A} / \mathrm{H}^{2}=4$ is considered as the atrium geometry aspect factor. This factor is of particular concern due to its influence on the prediction of the smoke layer. The atrium space is opened in the ground level with two opposite doors $10 \mathrm{~m}$ length $\times 3 \mathrm{~m}$ height. At the ceiling, the roof exhaust fans are installed with $1.5 \mathrm{~m}$ diameter equally spaced from side walls. The ground is assumed to have a ceramic tile finishing. Walls and ceiling are assumed to be of concrete with plaster layer.

\section{Fire representation}

The simulated fire is a circular pool fire placed at the center of the ground with a steady fire of $3 \mathrm{MW} / \mathrm{m}^{3}$ at $0.5 \mathrm{~m}$ above ground. The pool is slightly elevated to ensure its insulation. Thus, there is no fire spread in this scenario. Ignoring a combustion model has been accepted for the fire modeling community though it would provide less but practically acceptable accuracy,${ }^{15}$ The temperature inside the atrium is $27^{\circ} \mathrm{C}$.

\section{Boundary conditions}

An atmospheric pressure boundary is assumed and it is kept fixed, the occurrence of a reverse flow is permitted at each opening without an implied velocity (inlet velocity to the doors), i.e. Dirichlet Conditions. Given the walls and ceiling materials, adiabatic boundary conditions are assumed at all the walls, i.e. Neumann Conditions. Previous research disregarded the radiation portion; the full heat release rate is presented as $100 \%$ convective. This agrees with the experimental results and the scenarios in which radiation would not augment the spread of fire like the case presented here. In an atrium, plume temperatures are relatively low, so radiative losses are negligible within the atrium. When modeling the walls as adiabatic, no heat is lost by conduction through the walls..$^{33}$ The expected inaccuracy from disregarding radiation would result in differences in temperatures of walls and room interior. In addition, this assumption is argued to be rational according to some recommendations..$^{15}$

\section{Simulated domain}

The computational domain considers the atrium interior space being enclosed by three different boundary surfaces, namely the walls, the door vents and the fans. The fans are considered open vents with pressure outlets, while the door vents at the side walls of the atria are considered pressure inlets. The exhaust fans are modeled by applying an outward negative gage pressure. This will account for the fans' flow rates and velocities under different operating conditions to force the smoke flow out to the exterior of the atrium domain. The Grid is constructed by a cluster technique that enables a resolution of $8 \mathrm{~cm}$ at the fire surface and of $30 \mathrm{~cm}$ at the walls. The grid gets denser when approaching the ceiling to resolve the flow field of the buoyant smoke layer with operating roof exhaust fans. Two crossing planes passing through the pool fire and the door vents on both sides are taken to compare the predicted results as shown in Figure 1. Transient simulation of flow, energy, turbulence and species equations are solved for the atrium domain. A control volume approach is utilized for discretizing the whole domain into finite volumes (cell faces in $3 \mathrm{D}$ ), while an iterative algorithm is utilized to solve the linearized set of equations. Temporal derivatives are solved for each time step by an implicit scheme with second order accuracy. Pressure-velocity coupling is obtained by utilizing an algorithm that is a member of the SIMPLE family of pressure-velocity coupling algorithms which is modified to better suit transient calculations. A second order discretization scheme is used with momentum, density, temperature, turbulence and species transports. Since air and smoke flow inside the domain is buoyancy dominated, body force has been accounted for in turbulence production/dissipation and in pressure interpolation 
among cell faces. For the introduced model, the flame is simulated as a flow rate of exhaust $\mathrm{CO}_{2}$ gas that is dispersed in air inside the atrium (single phase) in accordance with the published experimental pool fire tests. ${ }^{25}$ Meanwhile, transient simulation was carried out to investigate the compartment's environment change due to the steady fire. The air/ smoke domain is modeled as an ideal gas whose properties depend only on temperature as specific heats, viscosity, thermal conductivity, mass diffusivity and thermal diffusivity. Despite being recommended by previous research work in buoyancy-driven flow, Boussinesq approximation is not used due to the presence of high temperature gradient in the smoke plume and the expectation of high body forces from buoyancy; ${ }^{15}$ while Boussinesq approximation ignores variation in fluid properties other than density, and density appears only when multiplied by gravity acceleration. Standard near wall function is used to resolve turbulent hot smoke jet near the ceiling and the side walls. An earlier research used the CFD model to compare the predicted results, based on 2D approximations, with those from an experiment conducted in a compartment fire facility at the United States Coast Guards' (USCG). Outcomes from that comparison regarding temperature and flow field have shown satisfactory agreements and demonstrated an accepted validity of the CFD model. ${ }^{28}$

\section{Results}

Pool fire was simulated in the middle of the floor level in a barrel of $1 \mathrm{~m}$ diameter and whose volume is $0.785 \mathrm{~m}^{3}$ filled with diesel fuel of mass $670 \mathrm{~kg}$ and density $850 \mathrm{Kg} / \mathrm{m}^{3}$. The total HRR of the fire is limited to $3 \mathrm{MW} / \mathrm{m}^{3}$. A $3 \mathrm{D}$ CFD model was constructed to solve the fluid flow governing equations of smoke from a fire in a small volume industrial facility atrium with Shape Coefficient $\zeta=4$. Detailed simulation was performed for the four numerical models shown in Table 1 with different number of operating exhaust fans and different out mass flow rates for the smoke through the fans. The HRR (3MW/ $\left.\mathrm{m}^{3}\right)$ and the $\mathrm{CO}_{2}$ emission rate $\left(2 \mathrm{Kg} / \mathrm{sec} / \mathrm{m}^{3}\right)$ are kept fixed. The fire and all the exhaust fans are initiated at $t=0$. The study focuses on optimizing the mechanical smoke control system to achieve the desired performance in terms of the domain temperature and the smoke ventilation rate Table 1 . The contour plots of the concentration of $\mathrm{CO}_{2}$, the total temperature and the velocity of the air within the domain are illustrated using two planes. One of the planes passes through the door vents while the other passes through the fans. The curves of the $\mathrm{CO}_{2}$ concentration, total temperature, and velocity values versus the height are plotted at four locations presented by vertical line segments whose Cartesian coordinates are indicated in Table 2. The results are taken when the simulated domain reaches the steady state condition. This is achieved after 10 minutes. At the $10^{\text {th }}$ minute, the results of the numerical analysis were as follows.

\section{The concentration of carbon dioxide}

The $\mathrm{CO}_{2}$ concentration in model 1 was homogeneous all over the smoke layer and the domain with an average value of 1575 ppm at $3 \mathrm{~m}$ height. As seen in Figure 2, the contours show that the $\mathrm{CO}_{2}$ concentration at the door vents' cross section is less than its concentration at the fans' cross section due to the entrainment of air with high velocity at the height level of the door vents. Model 2 showed significant difference in the $\mathrm{CO}_{2}$ concentration as the flow rate increased to $36.2 \mathrm{~m}^{3} / \mathrm{sec}$ versus $21.8 \mathrm{~m}^{3} / \mathrm{sec}$ in model 1 , for the same number of operating fans. The concentration differs among the four locations with the highest concentration at location 1 . The average value of $\mathrm{CO}_{2}$ concentration is $950 \mathrm{ppm}$ at $3 \mathrm{~m}$ height which is less than that of model 1. This is due to the increase in the speed of the fans, so the fans extract $\mathrm{CO}_{2}$ from the smoke layer with higher rate Figure 3.

Table I Different simulated models.

\begin{tabular}{lll}
\hline Models & flow rate/ fan & Number of fans \\
\hline Model 1 & $21.8 \mathrm{~m}^{3} / \mathrm{sec}$ & 2 \\
Model 2 & $36.2 \mathrm{~m}^{3} / \mathrm{sec}$ & 2 \\
Model 3 & $21.8 \mathrm{~m}^{3} / \mathrm{sec}$ & 3 \\
Model 4 & $36.2 \mathrm{~m}^{3} / \mathrm{sec}$ & 3
\end{tabular}

Table 2 Cartesian coordinates and locations of the line segments.

\begin{tabular}{cll}
\hline Lines & Start and end points & $\begin{array}{l}\text { Location } \\
\text { In the corner beside the left } \\
\text { door } 1\end{array}$ \\
Line 2 & $(4,0,4),(4,10,4) .0,10),(5,10,10)$ & $\begin{array}{l}\text { In front of the door vent } \\
\text { Beside the exhaust fan vertical } \\
\text { Line } 3\end{array} \quad \begin{array}{l}(10,0,16),(10,10,16) \\
\text { operating line }\end{array}$ \\
Line 4 & $(10,0,17),(10,10,17)$ & $\begin{array}{l}\text { Passes vertically through the } \\
\text { operating fan. }\end{array}$ \\
\hline
\end{tabular}
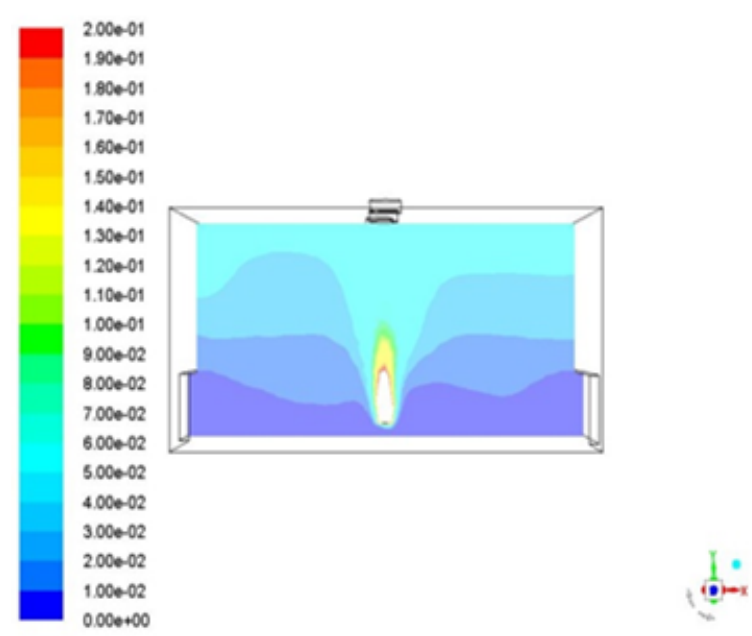

Figure 2(A) Door vents section.
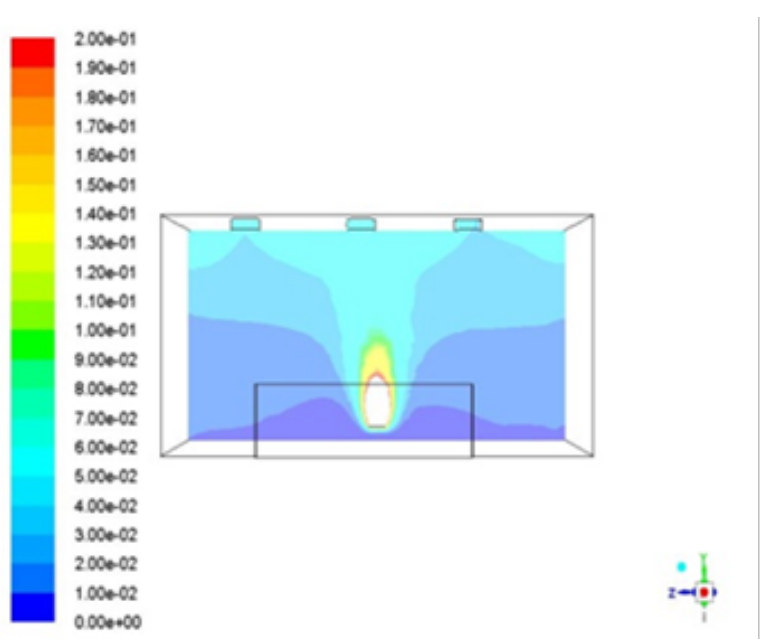

Figure 2(B) Fans section. 


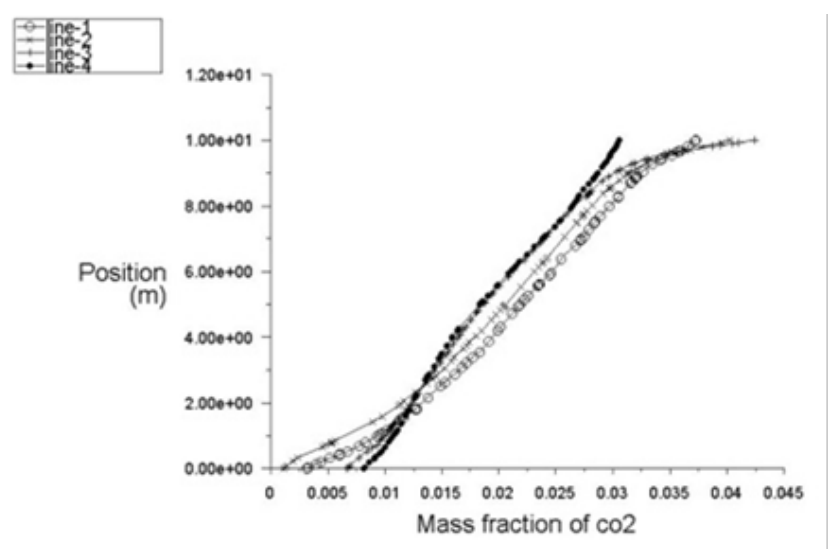

Figure 2(C) $\mathrm{CO} 2$ at the four vertical lines

Figure $2 \mathrm{CO} 2$ concentrations for model I.

Concentration contours show no significant improvement in model 3 than model 2. The $\mathrm{CO}_{2}$ concentration recorded an average value of $920 \mathrm{ppm}$ at $3 \mathrm{~m}$ height. Yet, it should be noted that $\mathrm{CO}_{2}$ concentration becomes less than model 2 at line 4 under the operating fan. Figure 4(C) shows the improvement in the $\mathrm{CO}_{2}$ concentration for the location near the fans Figure 4. By increasing the flow rate of the extracted smoke and the number of operating fans, less concentration of $\mathrm{CO}_{2}$ was recorded in model 4 , with an average value of $500 \mathrm{ppm}$ at $3 \mathrm{~m}$ height, but inhomogeneity was observed in the smoke layer Figure 5.

\section{The temperature}

In model 1, at the door section, the air temperature increases with time vertically downwards within the domain to reach an average value of $47^{\circ} \mathrm{C}$ (at the $10^{\text {th }}$ minute) at a height of $3 \mathrm{~m}$ above the ground level except at the fire core zone. The same behavior was observed at the fans section but with a higher average temperature value of $51^{\circ} \mathrm{C}$. This is due to the atrium's geometry and the absence of ventilation at the corners. At line 4 , the outflow temperature was $81^{\circ} \mathrm{C}$ while the temperature of the fire core reaches $1617^{\circ} \mathrm{C}$ Figure 6 . By increasing the outflow rate of the two operating fans in model 2, it was observed that plug-holing happened between the $30^{\text {th }}$ second and the second minute. After the second minute, plug-holing disappeared causing an unexpected reduction in the temperature of the fire core to record 1497 ${ }^{\circ} \mathrm{C}$. The average temperature of the door section was $37{ }^{\circ} \mathrm{C}$ and of the fan section was $44{ }^{\circ} \mathrm{C}$ at a height of 3 meter from the ground with an exhaust temperature of $60^{\circ} \mathrm{C}$ Figure 7 . Homogeneity is achieved in model 3 by operating three exhaust fans. An average temperature of $39^{\circ} \mathrm{C}$ was recorded at the door and fan sections at a height of $3 \mathrm{~m}$ above the ground level. Exhaust air temperature is reduced to the value of $51{ }^{\circ} \mathrm{C}$ due to the increase in the amount of entrained air. At the same time the fire core temperature increased to $1667{ }^{\circ} \mathrm{C}$ Figure 8 . By increasing the flow rate in model 4 , the average temperature at the door vent section was $31^{\circ} \mathrm{C}$ and at the fans section it was $37^{\circ} \mathrm{C}$ at a height of $3 \mathrm{~m}$ from the ground. The exhaust air temperature reached $38^{\circ} \mathrm{C}$. Yet, the temperature of the fire core increased to the value of $1777^{\circ} \mathrm{C}$ Figure 9.

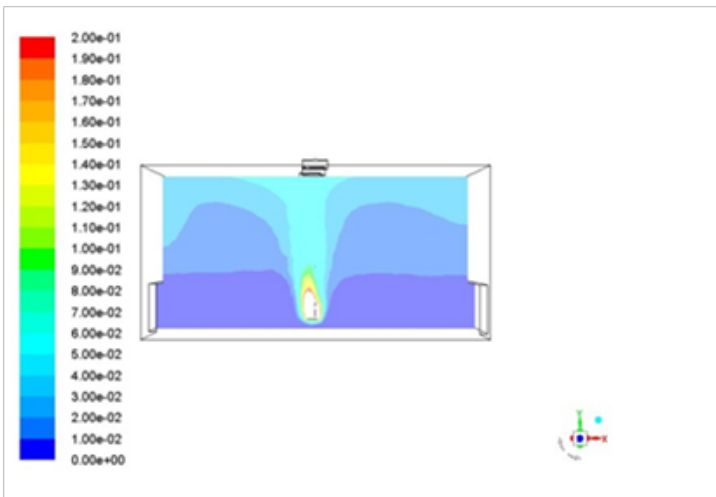

Figure 3(A) Door vents section.

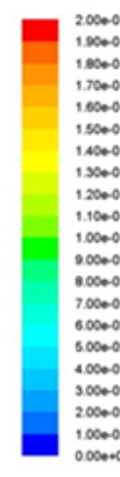

Figure 3(B) Fans section.

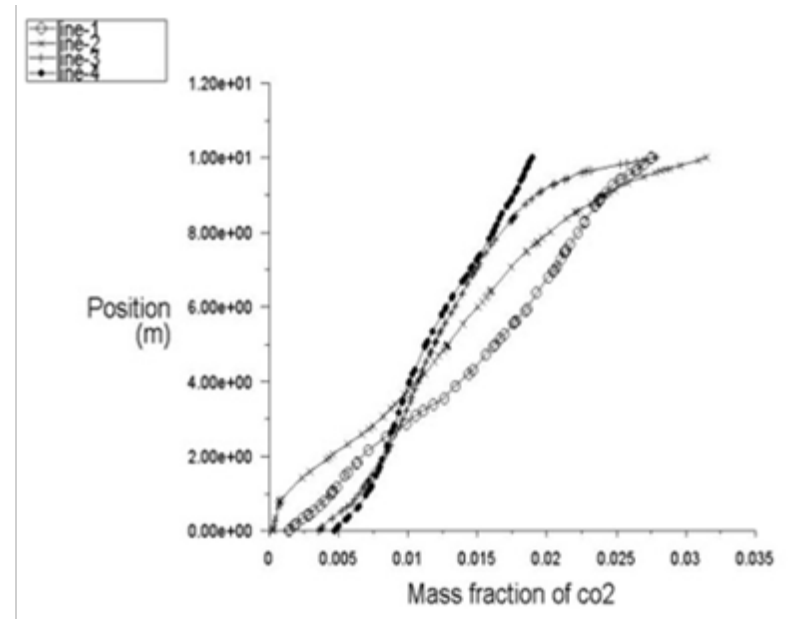

Figure $3 \mathrm{CO}_{2}$ concentration for model 2 .

Figure $3(\mathrm{C}) \mathrm{CO}_{2}$ versus the height 


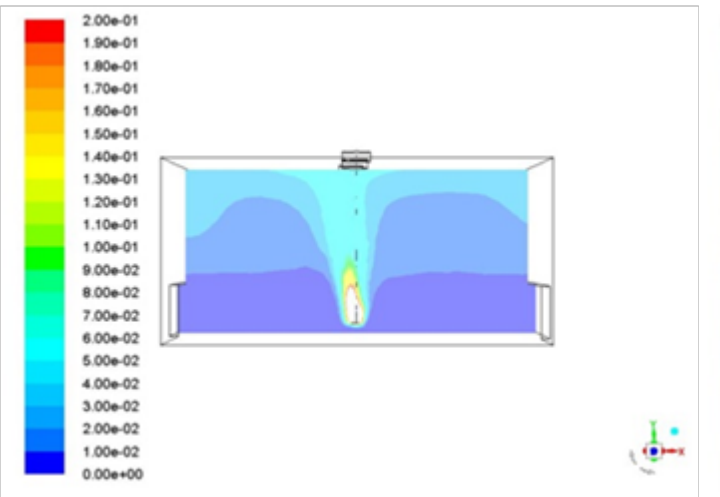

Figure 4(A) Door vents section.

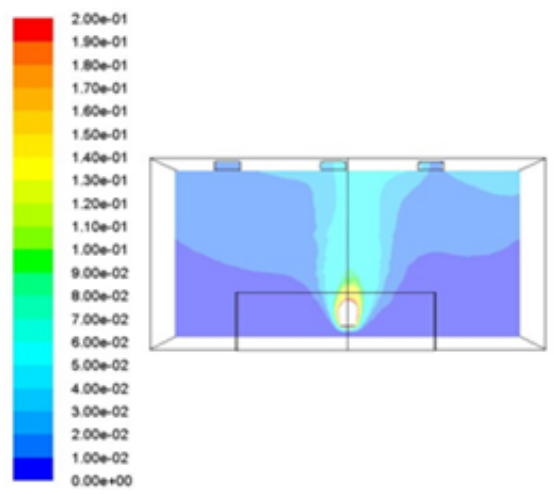

Figure 4(B) Fans section.

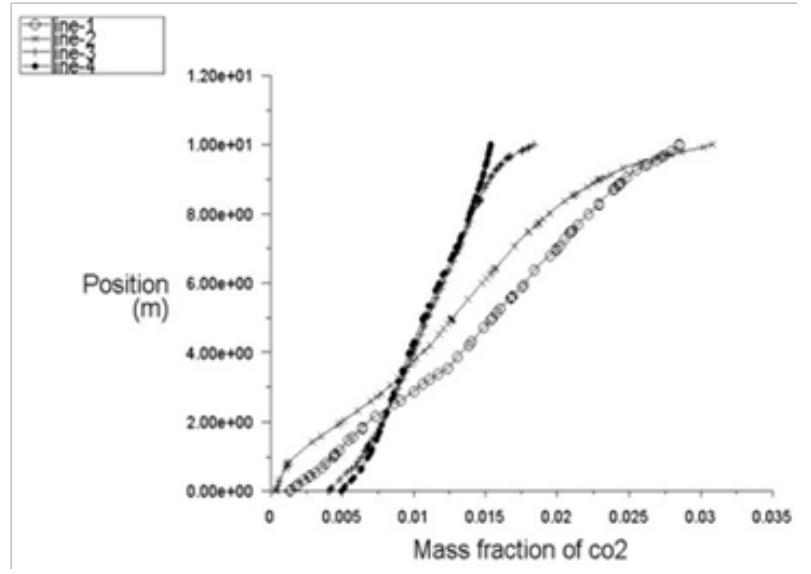

Figure 4(C) $\mathrm{CO}_{2}$ versus the height.

Figure $4 \mathrm{CO}_{2}$ concentration for model 3 .

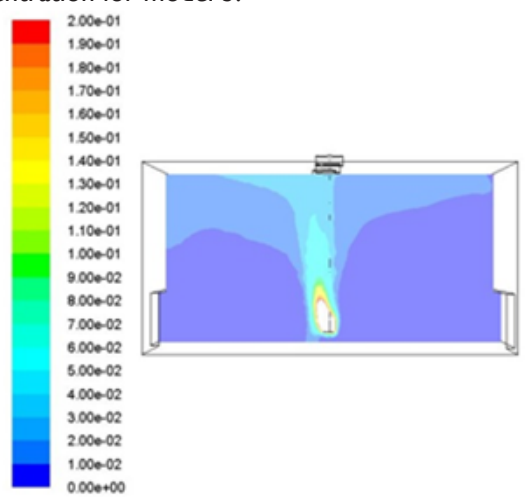

Figure 5(A) Door vents section.

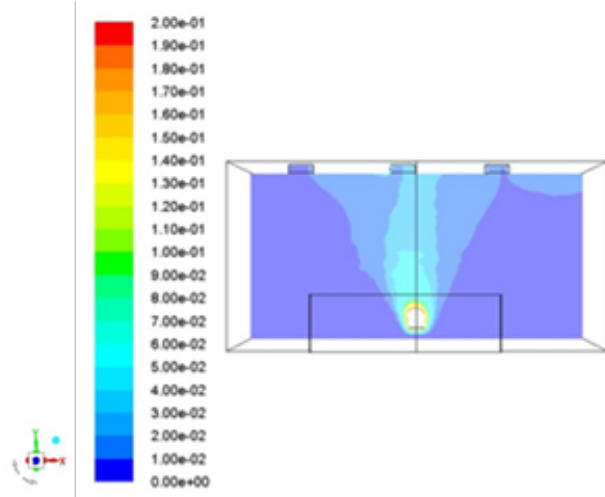

Figure 5(B) Fans section.

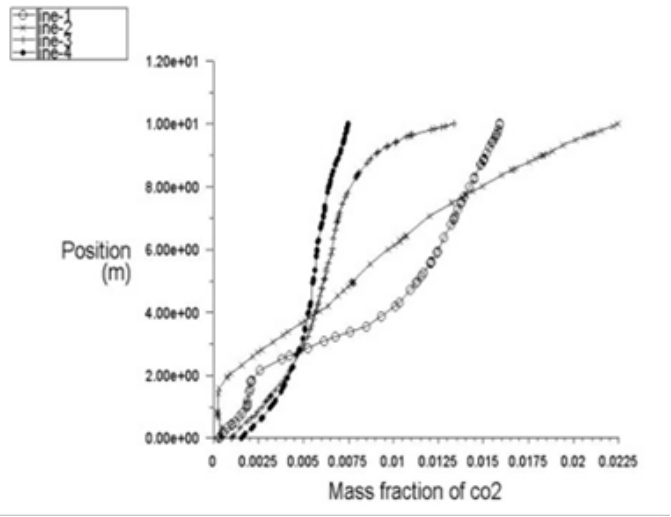

Figure $5 \mathrm{CO}_{2}$ concentrations for model 4 .

Figure $\mathbf{5}(\mathrm{C}) \mathrm{CO}_{2}$ versus the height. 


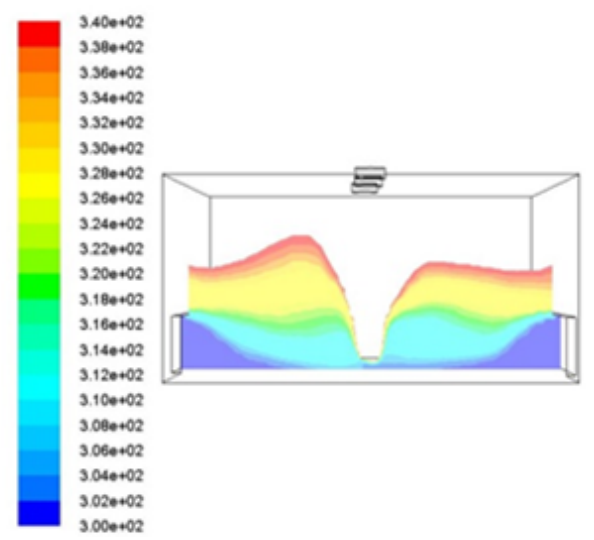

Figure 6(A) Door vents section

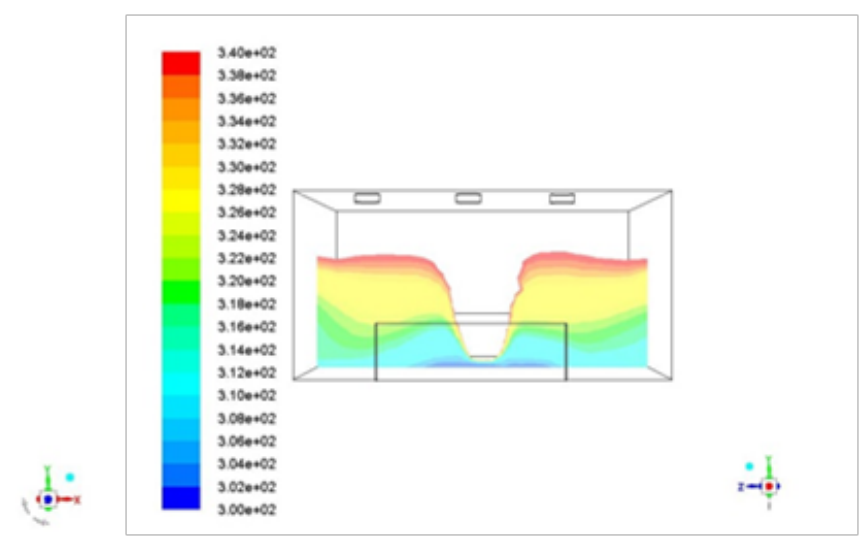

Figure 6(B) Fans section.

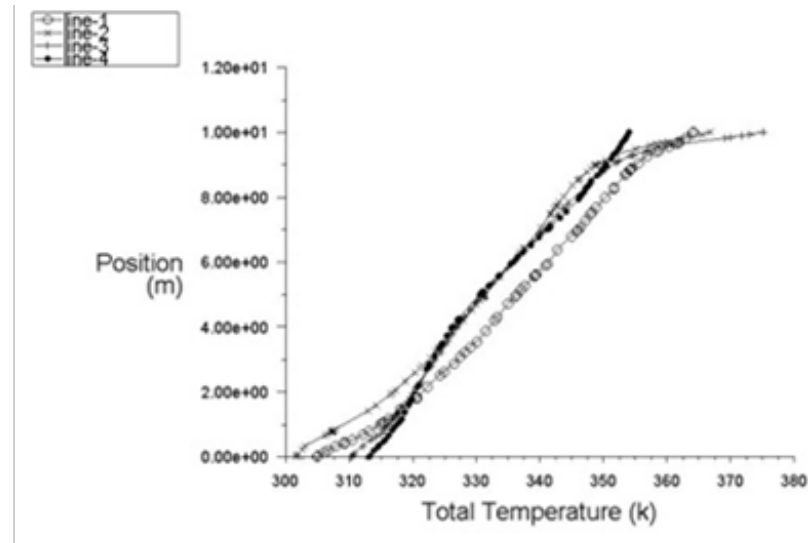

Figure 6(C) Temperature versus the height.

Figure 6 Temperature contours for model I.

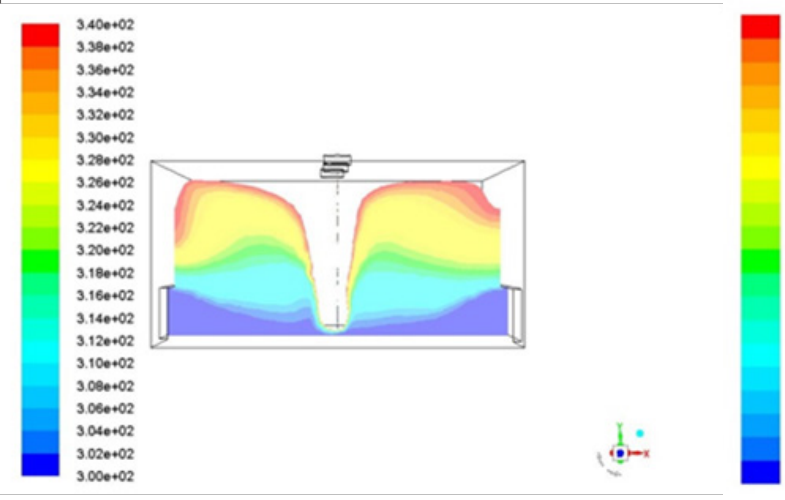

Figure 7(A) Door vents Section.

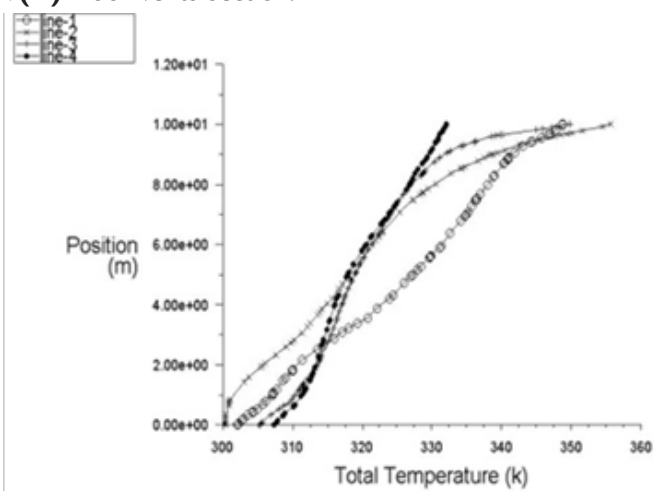

Figure $\mathbf{7}(\mathbf{C})$ Temperature versus the height.

Figure 7 Temperature contours for model 2. 


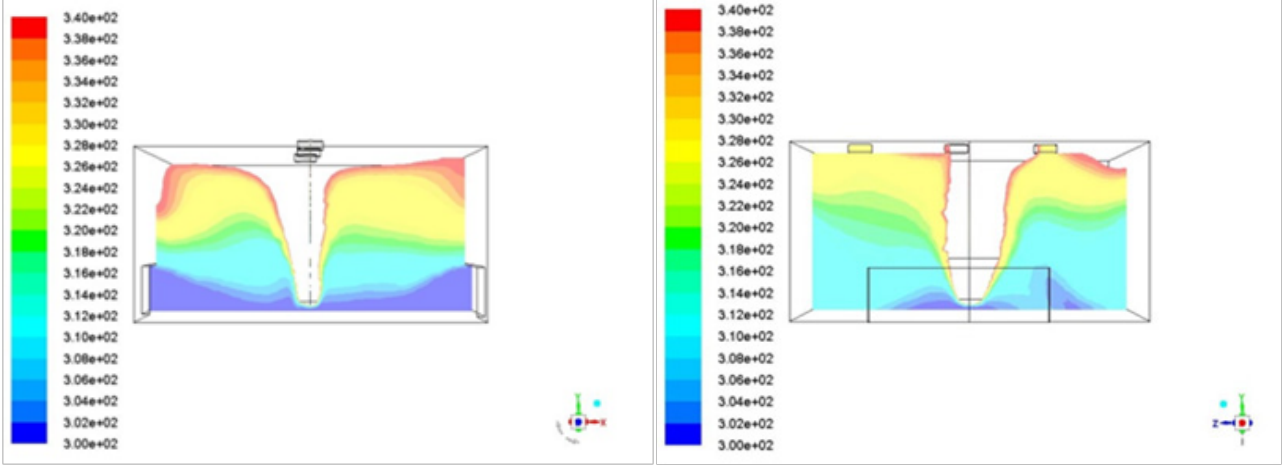

Figure 8(A) Door vents section.

Figure 8(B) Fans section.

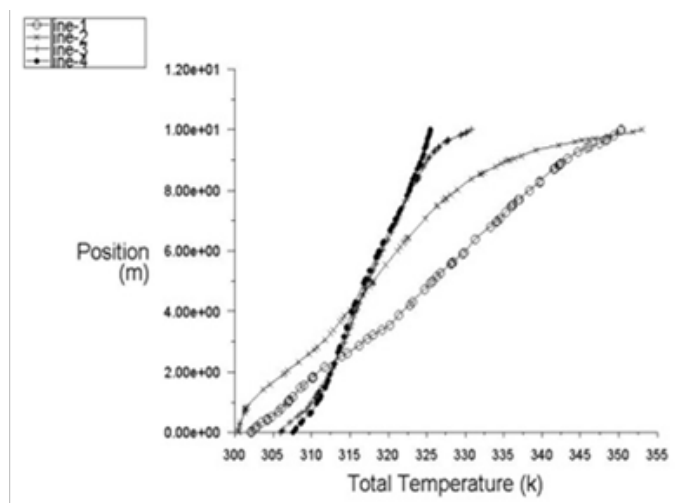

Figure $\mathbf{8 ( C )}$ Temperature versus the height.

Figure 8 Temperature contours for model 3.
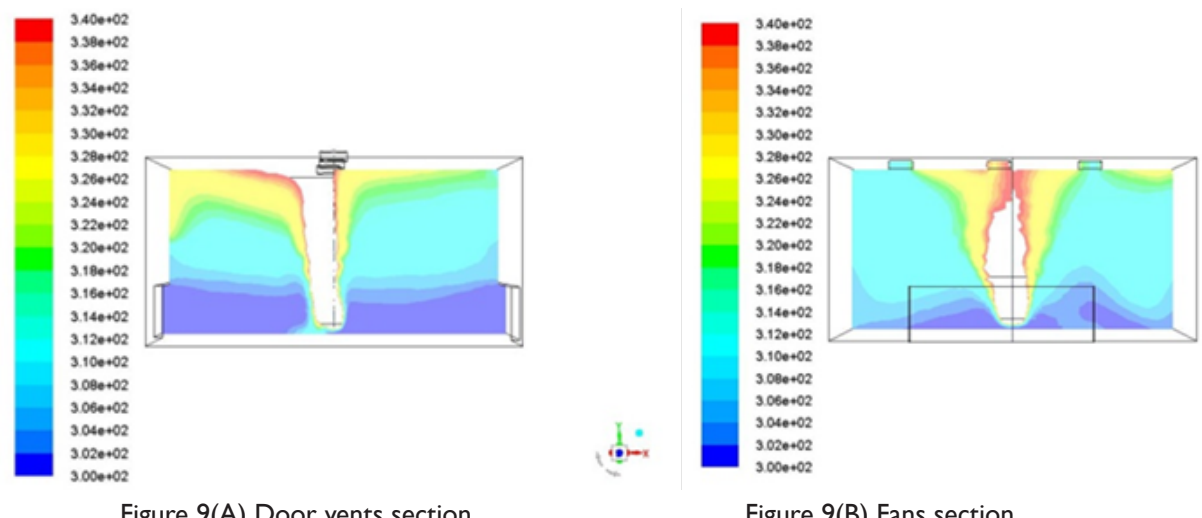

Figure 9(A) Door vents section.

Figure 9(B) Fans section

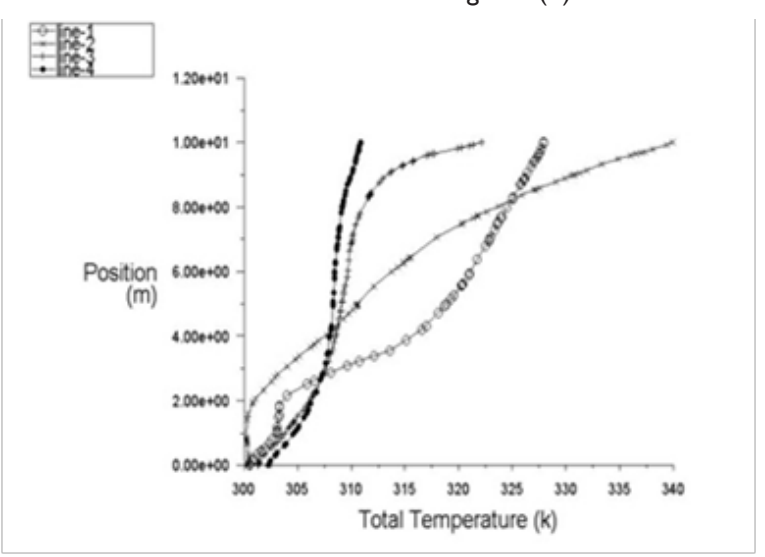

Figure $\mathbf{9 ( C )}$ Temperature versus the height.

Figure 9 Temp contours for model 4 . 


\section{The velocity of air in the atrium}

The velocity predictions for the four models show the entrainment of the outdoor air to the domain through the doors vent and the outflow through the fans in the ceiling. The rate of the inflow air depends on the fans' speed. Two different fans' speed, with implemented air velocity of $10 \mathrm{~m} / \mathrm{sec}$ and $18 \mathrm{~m} / \mathrm{sec}$, were used in the examined four models. From the predictions, it was observed that the outflow velocity for model 1 and model 3 was $10 \mathrm{~m} / \mathrm{sec}$ and for model 2 and model 4 was $18 \mathrm{~m} / \mathrm{sec}$. These values caused variation in the velocity values in front of the door vent and also in the circulation zones. By increasing the fans' speed, the maximum velocity of the entrained air was achieved at line 2 , in the lower half of the atrium, at heights which is higher in model 2 than in model 1 due to the air flow pattern suction upwards. This causes a reduction in the concentration of $\mathrm{CO}_{2}$ in the lower levels in model 2. By increasing the number of operating fans in model 3 and model 4, with the same fans' speed as in the first two models, the entrained air increases. This increase dilutes the concentration of $\mathrm{CO}_{2}$ and lessens the temperature near the floor levels. These outcomes will facilitate the evacuation during fire situations. The velocity contours for the four models are shown in Figures 10-13.

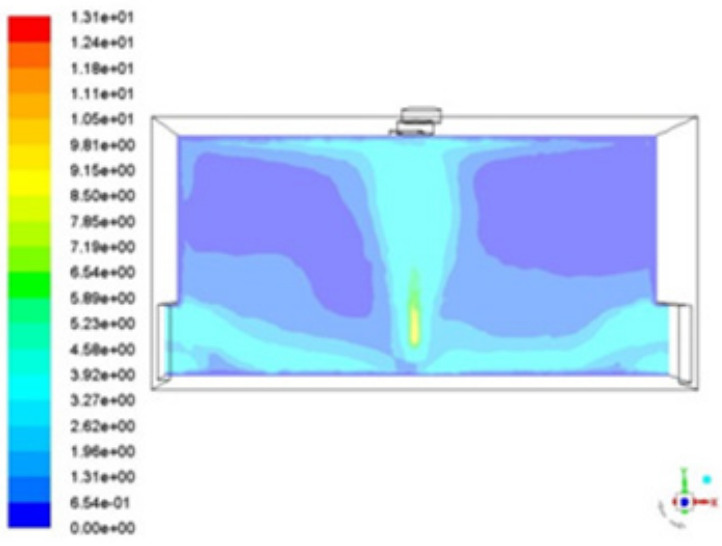

Figure 10(A) Door vents section.

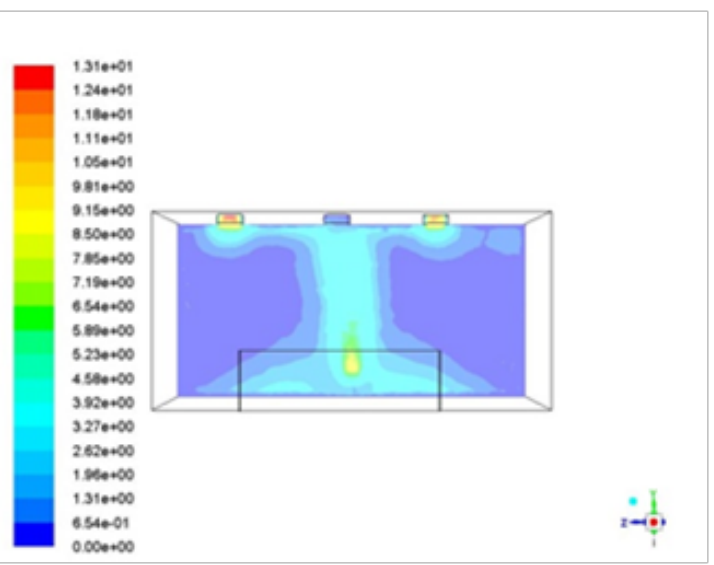

Figure IO(B) Fans section.

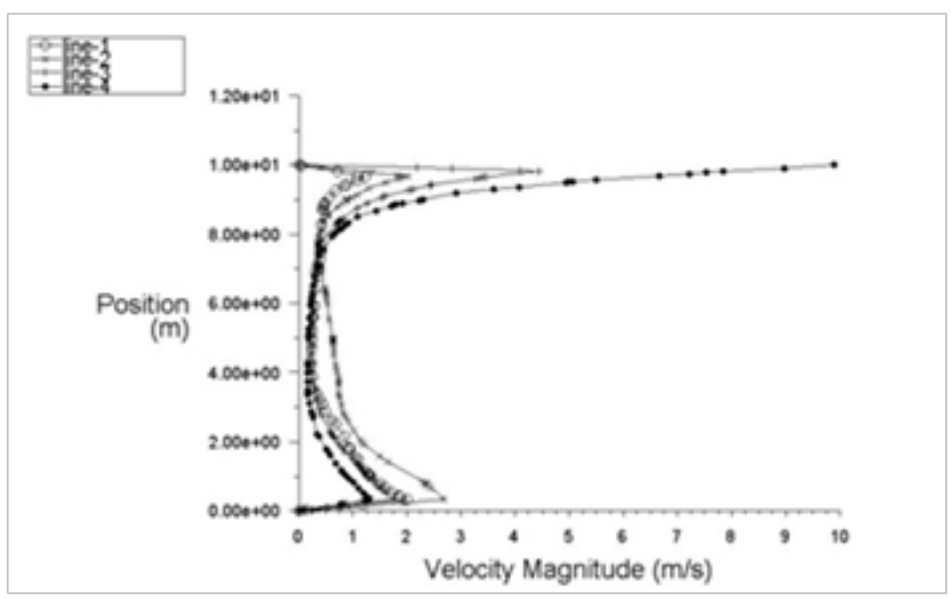

Figure 10 Velocity contours for model I.

Figure $\mathbf{1 0 ( C )}$ Velocity at the four vertical lines.

\section{Discussion}

From the results, it is observed that model 1 with two exhaust fans of flow rate $21.8 \mathrm{~m}^{3} / \mathrm{sec}$, recorded the highest concentration of carbon dioxide $(1575 \mathrm{ppm})$ and the highest temperatures $\left(47^{\circ} \mathrm{C}-51^{\circ} \mathrm{C}\right)$. Increasing the flow rate of the two fans in model 2 to $36.2 \mathrm{~m}^{3} / \mathrm{sec}$ improved both the concentration of carbon dioxide (950 ppm) and the temperatures $\left(37^{\circ} \mathrm{C}-44^{\circ} \mathrm{C}\right)$, but with the occurrence of plug-holing which might compromise the effectiveness of the smoke exhaust system. Increasing the number of exhaust fans to 3 with flow rate $21.8 \mathrm{~m}^{3} / \mathrm{sec}$ in model 3 , the reduction in the concentration of carbon dioxide $(920 \mathrm{ppm})$ and the temperatures $\left(39^{\circ} \mathrm{C}\right)$ was not remarkable, but homogeneity was achieved in both of them with no indication of plug-holing. Model 4, with 3fans and flow rate $36.2 \mathrm{~m}^{3} / \mathrm{sec}$, recorded the minimum decrease in the concentration of carbon dioxide $(500 \mathrm{ppm})$ and in the temperatures $\left(31^{\circ} \mathrm{C}-37^{\circ} \mathrm{C}\right)$, but it also recorded the maximum increase in the fire core and the smoke layer was nonhomogeneous. This is due to the effect of high flow rates of the fans on the increase of the fire release rate, despite having the advantage of reducing the temperature and decreasing the toxicity. Then, high flow rates encompass the risk of fire growth and the destruction of any smoke stratification. ${ }^{34}$ Then, model 3 is considered the optimum model for smoke evacuation in an atrium of the given dimensions. 


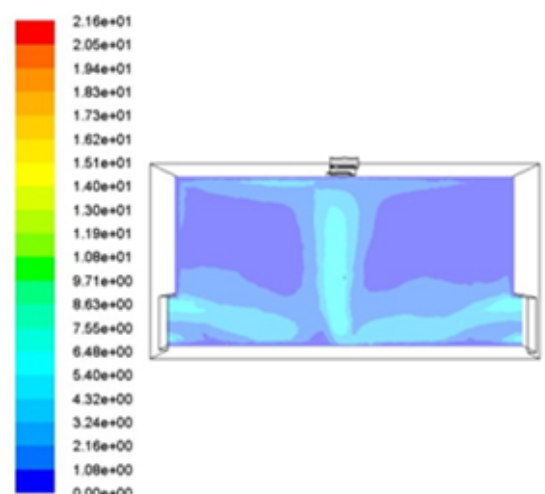

Figure I I(A) Door vents section.

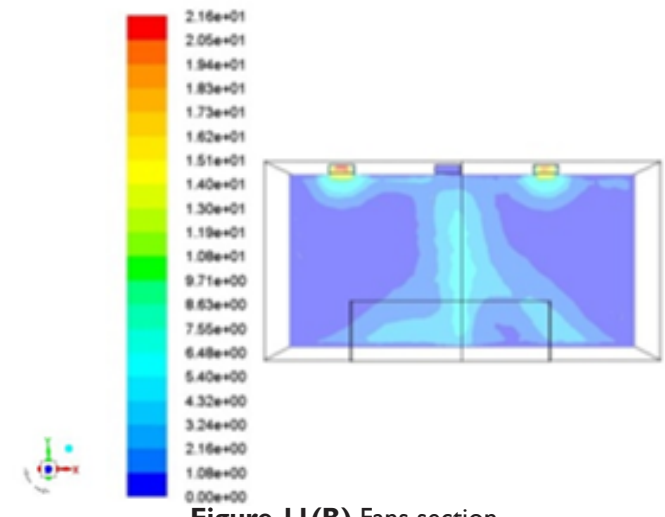

Figure I I(B) Fans section.

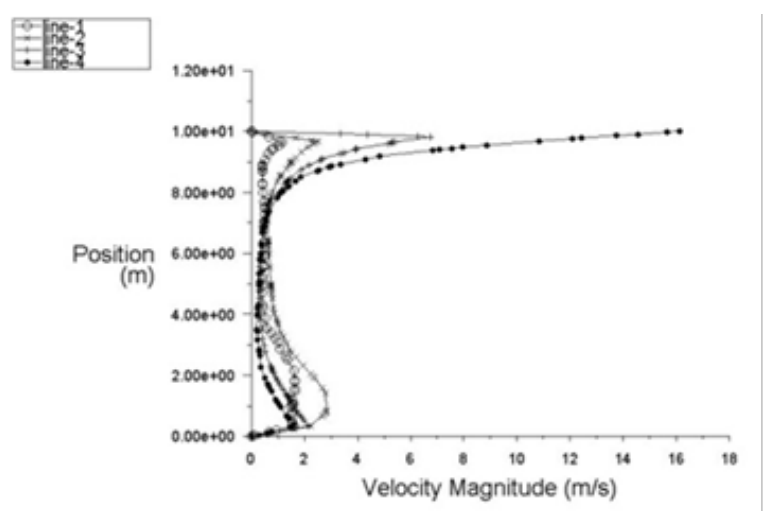

Figure II (C) Velocity at the four vertical lines.

Figure I I Velocity contours for model 2.

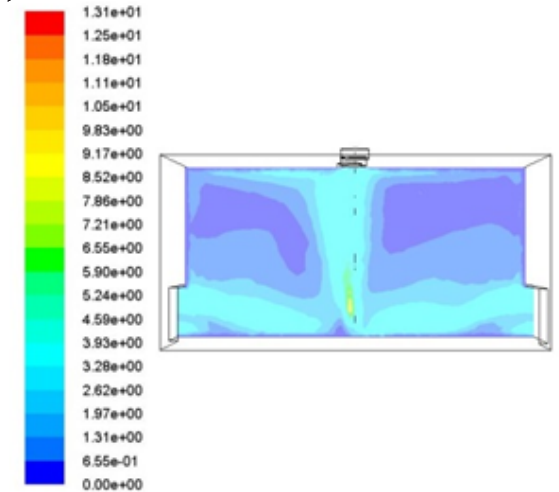

Figure I2(A) Door vents section

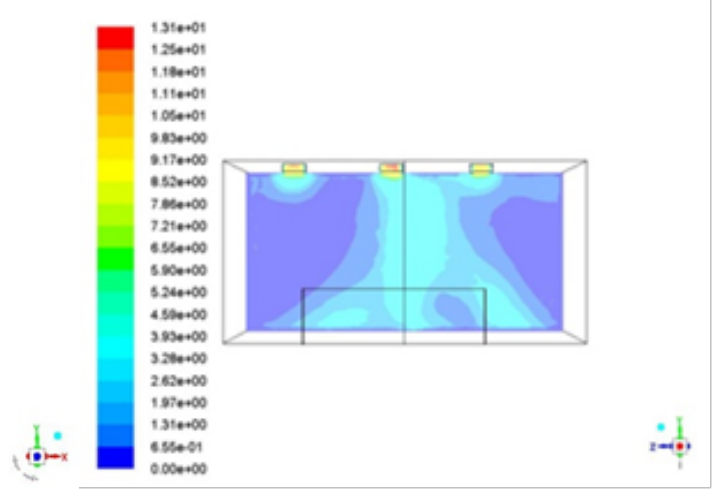

Figure I2(B) Fans section.

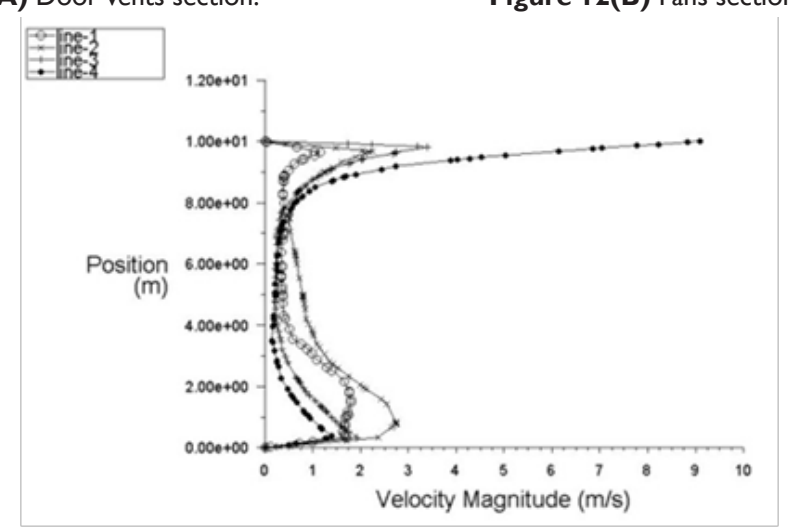

Figure I2(C) Velocity at the four vertical lines.

Figure 12 Velocity contours for model 3. 


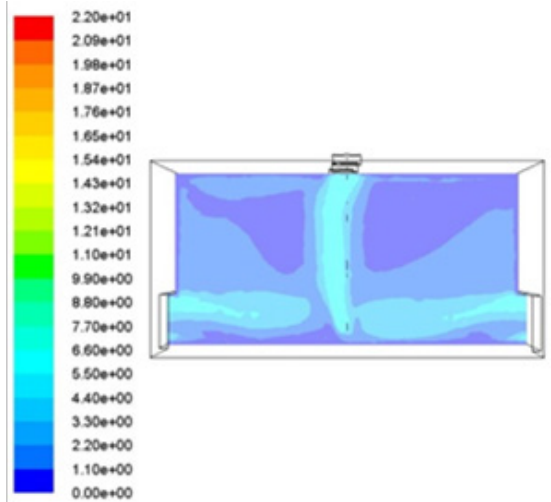

Figure I3(A) Door vents section.

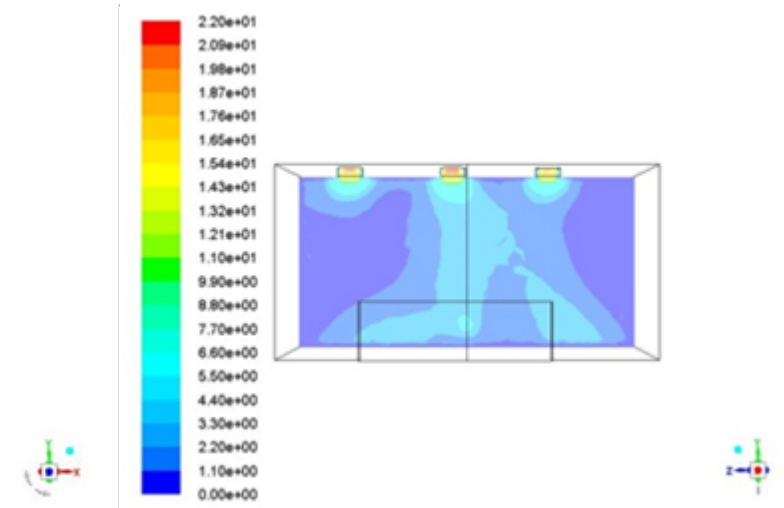

Figure 13(B) Fans section.

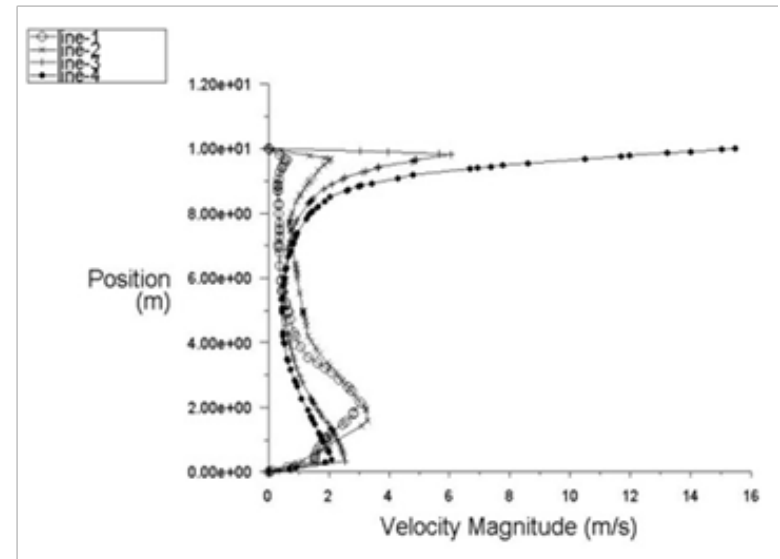

Figure 13 Velocity contours for model 4

Figure I3(C) Velocity at the four vertical lines.

\section{Conclusion}

Based on the conducted investigations for the performance of smoke extraction systems in an industrial atrium, this study provided numerical measurements for the smoke removal effectiveness during fire situations. A fire event with mechanical smoke exhaust was simulated in an atrium space in an industrial facility using a CFD tool. Four numerical models were tested and their results were compared to decide the optimum number of smoke exhaust fans and the smoke extraction rate to increase the ASET, not only for workers to evacuate, but also to give them time to clear any flammable or combustible materials in the atrium. The predictions show an improvement in the atrium indoor environment at the lower levels by increasing the number of extracting points with adequate flow rate due to the renewal of the atrium's air to meet the requirements.

\section{Acknowledgments}

None.

\section{Conflicts of interest}

The author declares that there are no conflicts of interest.

\section{References}

1. Schabacker J, Bettelini M, Rudin Ch. CFD study of temperature and smoke distribution in a railway tunnel with natural ventilation system. 2001.

2. Caruso G, Ferroni L. Numerical Simulation of a fire scenario. $C F D$ letters. 2014;6(4):131-143.
3. Ji J, Gao ZH, Fan CG, et al. A study of the effect of plug-holing and boundary layer separation on natural ventilation with vertical shaft in urban road tunnel fire. International Journal of Heat and Mass Transfer. 2012;55(21-22):6023-6041.

4. Jun bin $X$, Cheng Z, Jun fei Z, et al. The study of influence factors of the mechanical smoke evacuation system in atrium buildings. Procedia Engineering. 2013;52:508-513.

5. Milter HE, Rockett JA. Users' Guide to First, a comprehensive SingleRoom Fire Model. NBSIR 87-3595. National Bureau of Standards. 1987.

6. Chow WK. A comparison of the use of fire zone and field models for simulating atrium smoke-filling processes. Fire Saf $J$ 1995;25(4):337-353.

7. Novozhilov V. Computational fluid dynamics modeling of compartment fires. Prog Energy Combust Sci. 2001;27(6):611-666.

8. Rho JS, Ryou HS. A numerical study of atrium fires using deterministic models. Fire Saf J. 1999;33(3):213-229.

9. Zhuman F, Hadjisophocleous G. A two-zone fire growth and smoke movement model for multi-compartment buildings. Fire Saf $J$. 2000;34(3):257-287.

10. Bari S, Naser J. Simulation of smoke from a burning vehicle and pollution levels caused by traffic jam in a road tunnel. Tunneling and Underground Space Technology. 2005;20(3):281-290.

11. Chang CH, Banks D, Meroney RN. Computational fluid dynamics simulation of the progress of fire smoke in large space building atria. Tamkang Journal of Science and Engineering. 2003;6(3):151-157.

12. Chow WK, Hung WY. On the fire safety for internal voids in high-rise buildings. Building and environment. 2003;38(11):1317-1325. 
13. Hua J, Wang J, Kumar K. Development of a hybrid field and zone model for fire smoke propagation simulation in buildings. Fire Saf J. 2005;40(2):99-119.

14. Chow WK, Yin R. A new model on simulating smoke transport with computational fluid dynamics. Build Environ. 2004;39(6):611-620.

15. Gobeau N, Ledin HS, Lea CJ. Guidance for HSE inspectors. Smoke movement in complex enclosed spaces: assessment of computational fluid dynamics. Health and Safety Laboratory. 2003.

16. Vasanth S, Tauseef SM, Abbasi T, et al. Multiple pool fires: Occurrence, simulation, modeling and management. J Loss Prev Process Ind. 2014;29:103-121.

17. Wegrzyński, W, Vigne G. Experimental and numerical evaluation of the influence of the soot yield on the visibility in smoke in CFD analysis. Fire Saf J. 2017;91:389-398.

18. Lougheed GD. Considerations in the design of smoke management for atriums. Costruction Technology Update. 2000;48.

19. Jenft A, Boulet P, Collin A, et al. Modeling of fire suppression by fuel cooling. Fire Saf J. 2017;91:680-687.

20. Su C, Yao CC. Performance measurement of a smoke extraction system for buildings in full-scale hot smoke test. Measurement 2016;93:340-350.

21. NFPA 92B: Guide for smoke management systems in malls, atria and large areas. National Fire Protection Association. Quincy, MA 02269-9101, USA. 2000.

22. Mei F, Tang F, Liang X, et al. Evolution characteristics of fire smoke layer thickness in a mechanical ventilation tunnel with multiple point extraction. Appl Therm Eng. 2017;111:248-256.

23. Sikanen T, Hostikka S. Predicting the heat release rates of liquid pool fires in mechanically ventilated compartments. Fire Saf J. 2017;91:266-275.

24. Tieszen SR, Nicolette VF, Gritzo LA, et al. Vortical structures in pool fire: observation, speculation, and simulation. Sandia National Laboratories: SAND96-2607. 1996.
25. Rawat R, Pitsch H, Ripoll JF. Large-eddy simulation of pool fires with detailed chemistry using an unsteady flame let model. Center for Turbulence Research. 2002

26. Zhou XC, Gore JP. A study of entrainment and flow patterns in pool fires using particle imaging velocimetry. NIST-GCR-97-706 (2000). 1997.

27. Steckler KD, Quintiere JG, Rinkinen WJ. Flow induced by fire in a compartment. Symposium (International) on Combustion. 1982;19(1):913-920.

28. Zhou XC, Gore JP, Howard R. Measurements and predictions of velocity field induced by pool fires. Proceedings of the Combustion Fundamentals and Applications. Combustion Institute/Central and Western States Mexican National Section: American Flame Research Committee; Apr. 1995;23-26.

29. Fouad M, El-Sawah G, El-Banhawy A. A comparison of CFD model predictions to a real scale pool fire test. $16^{\text {th }}$ International Conference on Computer Theory and Applications. 2006.

30. Poh W. Tenability criteria for design of smoke hazard management systems. EcoLibrium. 2011;32-37.

31. Benucci S, Uguccioni G. Fire Hazard Calculations for Hydrocarbon Pool Fires - Application of "fire Dynamics Simulator - FDS" to the Risk Assessment of an Oil Extraction Platform. Chemical Engineering Transactions. 2010;19.

32. Kajishima T, Taira K. Computational Fluid Dynamics, Incompressible turbulent flows. Chapter 7, Reynolds-Averaged Navier-Stokes Equations. $2016 ; 237-268$

33. Tilley N, Rauwoens P, Merci B. Verification of the accuracy of CFD simulations in small-scale tunnel and atrium fire configurations. Fire Saf J. 2011;46(4):186-193.

34. Tarada F. New Perspectives on the Critical Velocity for Smoke Control. Fourth International Symposium on Tunnel Safety and Security, Frankfurt am Main, Germany. 2010. 